\title{
Alcohol consumption in the Baltic Republics
}

Martin McKee, Joceline Pomerleau, Aileen Robertson, Iveta Pudule, Daiga Grinberga, Kamelija Kadziauskiene, Algis Abaravicius, Sirje Vaask

\begin{abstract}
Study objectives-Premature mortality associated with alcohol intake is of particular concern in several countries of the former Soviet Union. This study explored self reported alcohol consumption (beer, wine, spirits) and its determinants in the Baltic Republics.
\end{abstract}

Design-Cross sectional surveys conducted in 1997.

Settings-Estonia, Latvia and Lithuania.

Participants-Representative samples of adults age 19-64 (Estonia $n=2010$; Latvia $\mathrm{n}=2258$; Lithuania $\mathrm{n}=2139$ ).

Methods-Between country differences in the frequency of alcohol intake were estimated. The odds of consuming alcohol weekly according to socioeconomic characteristics (age, ethnicity, rural/urban area, education, income) were calculated using multiple logistic regression analyses, adjusting for all variables simultaneously.

Main results-The proportion of respondents consuming alcohol weekly varied by country $(p<0.001) \quad(\mathrm{men}$ : Estonia $=61 \%$ Latvia $=41 \%$ Lithuania $=55 \%$; women: Estonia $=26 \%$ Latvia $=8 \%$ Lithuania $=14 \%$ ). Within each country, this proportion decreased with age in both sexes $(p<0.001)$, and increased with income in women $(p<0.01)$. In Estonia, the odds of drinking alcohol weekly was significantly lower in respondents of Russian than of Estonian ethnicity (odds ratios (OR) and 95\% confidence intervals $(95 \% \mathrm{CI}): \mathrm{men}=0.51$ $(0.36,0.71)$; women $=0.57(0.39,0.81))$. In Lithuania, the odds was higher in highly educated men than in those with a low education level $(\mathrm{OR}=1.48 \quad(1.01,2.17))$. Daily alcohol intake was higher in Estonia than in the other countries, as was the percentage of respondents drinking heavily (equivalent to $80 \mathrm{~g} /$ day).

Conclusions-Approximately half the men and one in six women in the Baltic States reported consuming alcohol at least weekly. Age and income were the strongest and most consistent correlates of the likelihood of consuming alcohol weekly. Ethnic differences were observed only in Estonia.

(F Epidemiol Community Health 2000;54:361-366)

Alcohol is increasingly recognised as an important factor in the burden of premature mortality in all of the countries of central and eastern Europe, causing high death rates from, among others, injuries, cirrhosis, and heart disease. All of the republics in the European part of the former Soviet Union experienced marked improvements in life expectancy after the imposition of Gorbachev's anti-alcohol campaign in $1985 .{ }^{1}$ There is now considerable evidence that these changes can be attributed to the reduction in traditionally extremely high rates of alcohol related death. ${ }^{23}$

However, these improvements were short lived and life expectancy in each of the Baltic Republics has fallen since 1989, accompanied by removal, or failure to enforce, controls on alcohol imports and production. Again, work in Russia, which has experienced similar, although greater changes, has confirmed the importance of alcohol in these events. ${ }^{4}$

Although only one measure of alcohol related mortality, rates of chronic liver disease and cirrhosis have the advantage of relative specificity, compared with other causes where the contribution of alcohol may be more variable, such as injuries, and can be used to give an idea of the scale of the problem. Between 1990 and 1995, age standardised death rates from chronic liver disease and cirrhosis doubled in Estonia and Latvia, and increased by $50 \%$ in Lithuania, although each country experienced a slight fall in 1996, the latest year for which comparable data are available. ${ }^{5}$ These rates are, however, still almost double that seen in, for example, the United Kingdom.

Effective policy responses are required, which should, preferably, take account of information on how much is drunk and by whom. Unfortunately, there is a lack of such information in this region.

Official statistics on consumption are often derived from official sales data. However, this is of limited value in situations such as those in the Baltic Republics where there is extensive smuggling and illicit production. It has been estimated that $45 \%$ of alcohol consumed in Estonia is from illegal sources. The corresponding figure for Lithuania is $60-65 \%{ }^{6}$ Furthermore, such data provide no information on the distribution of drinking within the population.

The alternative is to conduct surveys that identify who is drinking and that can indicate what are the socioeconomic determinants of drinking. This paper reports the results of three such surveys, undertaken among the populations of each of the three Baltic Republics.

\section{Methods}

Surveys were conducted in each country in June 1997. The principal focus of the surveys was on nutrition but, in addition, questions on alcohol consumption were included. Respondents were asked how often they drank spirits 
Table 1 Characteristics of the study sample

\begin{tabular}{|c|c|c|c|c|c|c|}
\hline \multirow[b]{2}{*}{ Characteristics } & \multicolumn{3}{|l|}{ Men } & \multicolumn{3}{|l|}{ Women } \\
\hline & Estonia & Latvia & Lithuania & Estonia & Latvia & Lithuania \\
\hline \multicolumn{7}{|l|}{ Age group (y) } \\
\hline $19-34$ & 44.1 & 31.8 & 35.8 & 41.4 & 28.3 & 31.0 \\
\hline $35-49$ & 35.5 & 35.2 & 36.5 & 33.9 & 32.8 & 35.2 \\
\hline $50-64$ & 20.4 & 33.1 & 27.8 & 24.7 & 39.0 & 33.9 \\
\hline (n) & $(901)$ & (1055) & $(979)$ & (1109) & (1203) & (1160) \\
\hline \multicolumn{7}{|l|}{ Ethnicity } \\
\hline Estonian & 71.7 & & & 68.4 & & \\
\hline Latvian & & 55.6 & & & 53.7 & \\
\hline Lithuanian & & & 83.0 & & & 86.2 \\
\hline Russian & 22.4 & 33.5 & 9.3 & 24.9 & 36.1 & 7.5 \\
\hline Other & 5.9 & 10.9 & 7.7 & 6.7 & 10.2 & 6.3 \\
\hline (n) & $(901)$ & $(1055)$ & (979) & (1109) & (1202) & (1155) \\
\hline \multicolumn{7}{|l|}{ Region of living } \\
\hline Urban & 60.7 & 65.7 & 65.8 & 70.6 & 67.2 & 67.6 \\
\hline Rural & 39.3 & 34.3 & 34.2 & 29.4 & 32.8 & 32.4 \\
\hline (n) & $(901)$ & (1055) & (979) & (1109) & (1203) & $(1160)$ \\
\hline \multicolumn{7}{|l|}{ Education } \\
\hline Low & 15.1 & 21.0 & 22.2 & 10.4 & 17.3 & 18.4 \\
\hline Medium & 47.6 & 31.3 & 26.3 & 44.6 & 33.6 & 25.0 \\
\hline High & 37.3 & 47.7 & 51.5 & 45.0 & 49.1 & 56.6 \\
\hline (n) & (901) & $(1034)$ & $(974)$ & (1109) & (1179) & (1153) \\
\hline \multicolumn{7}{|l|}{ Income } \\
\hline Level 1-lowest & 24.6 & 34.9 & 40.3 & 30.8 & 38.5 & 36.5 \\
\hline Level 2 & 33.5 & 44.1 & 26.9 & 40.4 & 47.2 & 30.6 \\
\hline Level 3 & 28.2 & 12.9 & 11.1 & 22.8 & 9.5 & 11.9 \\
\hline $\begin{array}{l}\text { Level 4-highest } \\
\text { (n) }\end{array}$ & $\begin{array}{l}13.7 \\
(901)\end{array}$ & $\begin{array}{l}8.1 \\
(1006)\end{array}$ & $\begin{array}{l}21.7 \\
(903)\end{array}$ & $\begin{array}{l}6.0 \\
(1109)\end{array}$ & $\begin{array}{l}4.8 \\
(1169)\end{array}$ & $\begin{array}{l}21.0 \\
(1114)\end{array}$ \\
\hline
\end{tabular}

( $>22^{\circ}$ proof), beer, or wine. Possible responses were daily, 2-3 times per week, once per week, 2-3 times per month, a few times per year, and never. Eleven respondents from Latvia and 11 from Lithuania were excluded from the analyses because they did not provide information on their usual intake of spirits, beer or wine. For the purposes of analysis, people were categorised as drinking at least weekly or less often.

Respondents were also asked how much of specified measures they had consumed in the preceding week. These were: spirits $(50 \mathrm{ml}$ measures), wine (100 $\mathrm{ml}$ glasses) and beer (500 $\mathrm{ml}$ bottles). These were converted to grams of alcohol, summed, and divided by seven to give the mean daily consumption.

The survey sought to include 3000 persons who were representative of the national population aged between 19 and 64 years (20 and 64 in Lithuania). In each country, the sampling frames were the National Population Registers. All interviews were conducted in the person's own homes during the summer of 1997. Inter-

Table 2 Frequency (\%) of drinking each type of beverage

\begin{tabular}{|c|c|c|c|c|c|c|c|}
\hline & & \multicolumn{2}{|c|}{ Estonia } & \multicolumn{2}{|c|}{ Latvia } & \multicolumn{2}{|c|}{ Lithuania } \\
\hline & & Men & Women & Men & Women & Men & Women \\
\hline \multirow[t]{6}{*}{ Spirits } & daily & 2.8 & 0.3 & 0.5 & 0.3 & 0.9 & 0.1 \\
\hline & $2-3$ times per week & 8.2 & 1.8 & 8.1 & 1.1 & 6.8 & 0.8 \\
\hline & once per week & 17.4 & 7.2 & 8.1 & 1.1 & 13.8 & 1.8 \\
\hline & $2-3$ times per month & 36.4 & 25.0 & 40.9 & 17.7 & 38.8 & 15.3 \\
\hline & several times per year & 23.9 & 43.3 & 31.7 & 52.3 & 31.8 & 57.7 \\
\hline & never & 11.3 & 22.5 & 10.9 & 27.4 & 8.0 & 24.3 \\
\hline \multirow[t]{6}{*}{ Beer } & daily & 12.6 & 1.5 & 3.6 & 0.0 & 7.5 & 0.1 \\
\hline & $2-3$ times per week & 21.0 & 4.9 & 9.9 & 3.4 & 24.9 & 3.2 \\
\hline & once per week & 15.5 & 9.2 & 19.4 & 1.0 & 16.3 & 5.7 \\
\hline & $2-3$ times per month & 18.6 & 12.6 & 24.8 & 9.5 & 22.0 & 13.1 \\
\hline & several times per year & 11.2 & 19.5 & 20.1 & 26.7 & 13.4 & 25.7 \\
\hline & never & 21.1 & 52.2 & 22.1 & 59.3 & 15.9 & 52.2 \\
\hline \multirow[t]{6}{*}{ Wine } & daily & 0.8 & 0.4 & 0.0 & 0.2 & 0.3 & 0.3 \\
\hline & $2-3$ times per week & 3.1 & 2.5 & 2.2 & 1.2 & 3.8 & 1.9 \\
\hline & once per week & 5.7 & 6.6 & 1.5 & 1.4 & 5.5 & 4.5 \\
\hline & several times per month & 16.0 & 20.8 & 17.2 & 29.4 & 16.0 & 17.4 \\
\hline & several times per year & 43.8 & 47.5 & 29.3 & 36.8 & 33.8 & 47.3 \\
\hline & never & 30.7 & 22.1 & 49.8 & 31.0 & 40.6 & 28.6 \\
\hline
\end{tabular}

views were conducted in both the national language of the country concerned and in Russian.

In Estonia, a simple random sample was drawn from the register. Interviewers did not return to a house if there was no reply and substitution was allowed if the response rate in the county in question was less than 60 per cent, which happened in seven of the 15 counties. Overall less than $5 \%$ of people were substituted. Interviews were conducted by public health specialists, nutritionists and people with previous interviewing experience. Each attended a one day initial training session. The response rate was $67.3 \%$.

In Latvia, two stage sampling was used, with the first stage selecting a sample for each of the 26 regions of Latvia according to population size. In the second stage, a random sample within the strata was selected. The exception was for the city of Riga, were there appeared to be problems with the population register data, with a disproportionate number of people registered in with ages over 60 . Consequently, in Riga, the second stage sample was also stratified by age group. Interviewers were recruited from the regional environmental health centres. Substitution was not permitted and interviewers would return to an address up to five times. Each received interviewer received training. The response rate was $77.7 \%$.

In Lithuania a sample of 3000 names was drawn at random from those people listed on the National Population Register who were living at addresses in Lithuania and were aged between 20 and 65 . Interviewers were mainly assistants working in hygiene stations, who underwent an initial training session. In most cases the interviewers returned to an address on multiple occasions if they were unable to find the subject. There was no substitution. The response rate was $74.1 \%$.

Most of the variables analysed are self explanatory. Education levels were divided into three categories. Low includes those with only primary level education. Medium includes those who have completed secondary education. High includes those who have completed specialist secondary or university education. The income variable relates to family income. In each country it was divided into four categories based on national criteria for the poverty level, with the poorest category considered to be living in severe poverty.

Data were analysed using the statistical package STATA (version 5.0; College Station, Texas). Between country variations in the proportion of respondents consuming alcohol at least once a week and in the proportion of heavy drinkers were assessed using $\chi^{2}$ tests. Differences in mean daily alcohol intake were estimated using analysis of variance (with Bonferroni multiple comparison tests). Age adjusted proportions were calculated as the values predicted by the logistic regression model with age held at its mean value. The odds of consuming alcohol weekly according sociodemographic characteristics were estimated using multiple logistic regression analyses with adjustment age only and for all the 
Table 3 Proportion of respondents consuming alcoholic beverages at least once a week, by gender, country and age group

\begin{tabular}{|c|c|c|c|c|c|c|}
\hline \multirow{2}{*}{$\begin{array}{l}\text { Type of alcohol and } \\
\text { age group }(y)\end{array}$} & \multicolumn{3}{|l|}{ Men } & \multicolumn{3}{|l|}{ Women } \\
\hline & Estonia \% & Latvia \% & Lithuania \% & Estonia \% & Latvia \% & Lithuania \% \\
\hline \multicolumn{7}{|l|}{ Any type of alcohol } \\
\hline All & 60.5 & 41.3 & $55.3^{\star \star \star}$ & 25.5 & 8.2 & $14.1^{\star \star \star}$ \\
\hline $19-34$ & 66.0 & 45.1 & $64.9^{\star \star \star \star}$ & 35.3 & 13.5 & $20.3^{\star \star \star}$ \\
\hline $35-49$ & 63.4 & 47.4 & $56.6^{\star \star \star}$ & 26.6 & 8.9 & $15.2^{\star \star \star}$ \\
\hline $50-64$ & 43.5 & 31.2 & $41.2^{\star \star}$ & 7.7 & 3.8 & $7.1^{\star}$ \\
\hline \multicolumn{7}{|l|}{ Beer } \\
\hline All & 49.2 & 33.2 & $48.4^{\star \star \star \star}$ & 15.8 & 4.6 & $9.0^{\star \star \star}$ \\
\hline $19-34$ & 59.2 & 38.8 & $61.4^{\star \star \star}$ & 23.1 & 6.5 & $13.4^{\star \star \star}$ \\
\hline $35-49$ & 47.2 & 35.0 & $48.7^{\star \star \star}$ & 16.5 & 5.6 & $9.1^{\star \star \star}$ \\
\hline $50-64$ & 31.0 & 25.8 & 31.3 & 2.6 & 2.4 & 4.8 \\
\hline \multicolumn{7}{|l|}{ Wine } \\
\hline All & 9.5 & 3.7 & $9.7^{\star \star \star}$ & 9.7 & 2.9 & $6.6^{\star \star \star}$ \\
\hline $19-34$ & 11.1 & 3.3 & $10.6^{\star \star \star}$ & 13.1 & 6.8 & $10.9^{\star}$ \\
\hline $35-49$ & 9.7 & 4.3 & $12.0^{\star \star}$ & 11.2 & 1.5 & $6.1^{\star \star \star}$ \\
\hline $50-64$ & 6.0 & 3.4 & 5.5 & 1.8 & 1.3 & 3.3 \\
\hline \multicolumn{7}{|l|}{ Spirits } \\
\hline All & 28.4 & 16.6 & $21.3^{\star \star \star \star}$ & 9.3 & 2.7 & $2.6^{\star \star \star}$ \\
\hline $19-34$ & 27.2 & 14.0 & $20.6^{\star \star \star \star}$ & 10.9 & 4.1 & $1.7^{\star \star \star \star}$ \\
\hline $35-49$ & 31.3 & 22.1 & $25.5^{\star}$ & 10.6 & 3.6 & $3.4^{\star \star \star}$ \\
\hline $50-64$ & 26.1 & 13.2 & $16.5^{\star \star \star}$ & 4.7 & 0.9 & $2.5^{\star \star}$ \\
\hline
\end{tabular}

$\bar{\star}$ Significant variations among countries within the gender specific age group, $\mathrm{p}<0.05 ;{ }^{\star \star} \mathrm{p}<0.01$; $\star \star \star \mathrm{p}<0.001$.

variables taken simultaneously. Because of their skewed distribution, values of daily alcohol intake were $\log _{\mathrm{e}}$ transformed before testing for significance; transformed values were returned to their original units in the results section. As sex is a strong determinant of drinking rates, results were analysed separately for men and women.

\section{Results}

Table 1 shows the sociodemographic characteristics of the samples.

Table 2 shows the frequency with which each type of alcohol is drunk. Very few people drink alcohol daily. The only group for whom this is
KEY POINTS

- Alcohol has played an important part in changing mortality patterns in the Baltic Republics in recent years.

- Although the three countries are superficially similar, there are important differences in patterns of alcohol consumption.

- Levels of consumption among the Russian populations in each country vary considerable and, in Estonia and Lithuania, differ significantly from that of the majority population.

- The three Baltic Republics, while sharing some similarities, also exhibit important differences.

at all common is male beer drinkers in Estonia. Many people who are not normally wine or spirit drinkers will do so a few times per year.

The proportion of people consuming alcohol every week varied by country (table 3 ), with, for both sexes, the highest rates found in Estonia, followed by Lithuania, and then Latvia. For both men and women, consumption declined with age. This was especially marked among women, where the proportion of those aged 50-64 drinking weekly was between a third and a fifth of that among those aged 19-34.

The commonest beverage, among both men and women and in all three countries, is beer, followed by spirits among men and wine among women (table 3). However, many men regularly consume more than one type of beverage, most often combining beer and spirits (fig 1).
Men in: Estonia

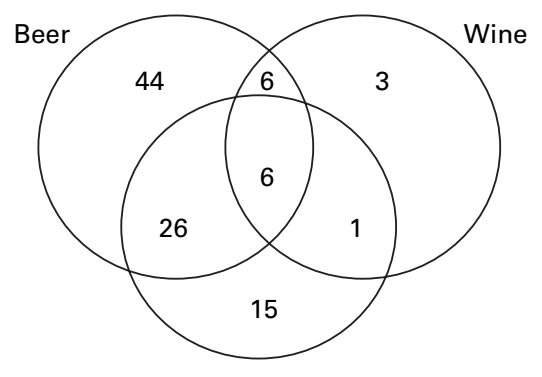

Spirits

Women in: Estonia

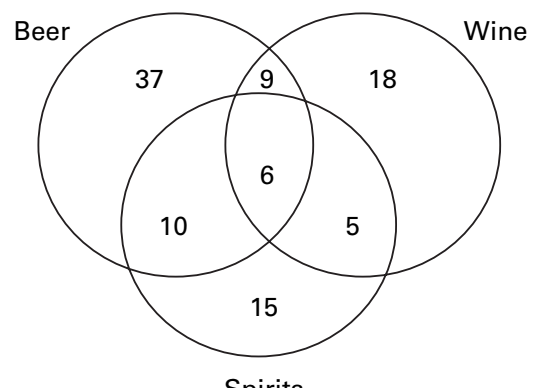

Spirits
Latvia

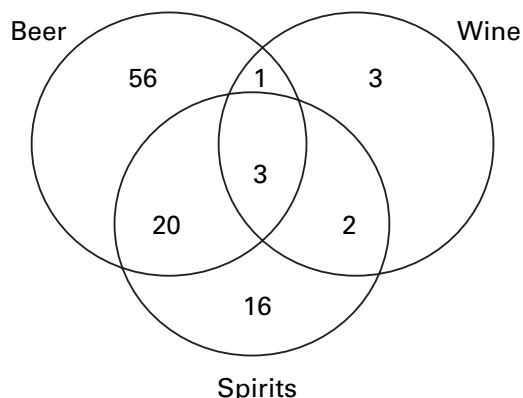

Spirits

Latvia
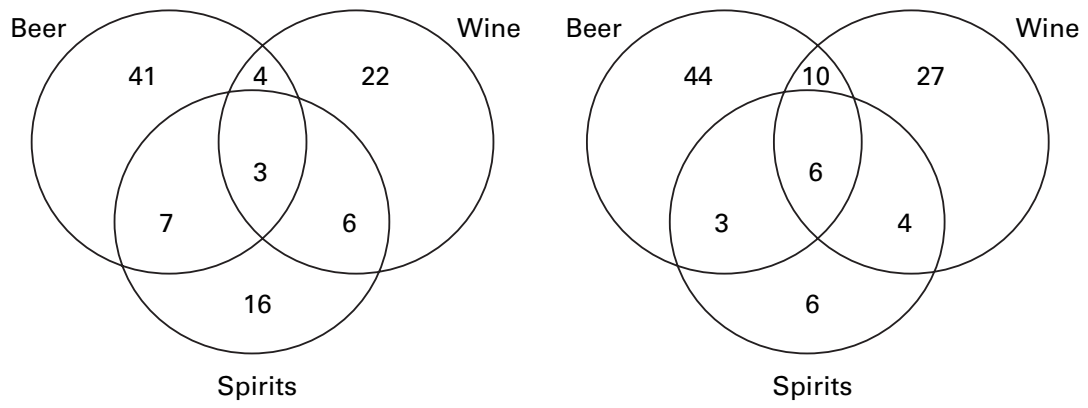

Figure 1 Proportion (\%) of respondents consuming beer, wine and spirits at least once a week, singly and in combination, by country and gender. 
Table 4 Age adjusted proportion of respondents consuming different types of alcohol at least once a week by gender, country and nationality

\begin{tabular}{|c|c|c|c|c|c|c|}
\hline \multirow{2}{*}{$\begin{array}{l}\text { Type of alcohol and } \\
\text { ethnic group }\end{array}$} & \multicolumn{3}{|l|}{ Men } & \multicolumn{3}{|l|}{ Women } \\
\hline & Estonia & Latvia & Lithuania & Estonia & Latvia & Lithuania \\
\hline \multicolumn{7}{|l|}{ All drinks } \\
\hline Estonian & 64.9 & & & 26.9 & & \\
\hline Latvian & & 41.2 & & & 7.1 & \\
\hline Lithuanian & & & 53.1 & & & 12.1 \\
\hline Russian & $51.2^{\star \star}$ & 40.4 & $69.4^{\star \star}$ & $17.1^{\star \star}$ & 8.4 & $24.4^{\star \star}$ \\
\hline Other & $46.3^{\star \star}$ & 43.9 & 64.0 & $13.5^{\star}$ & 4.7 & 12.5 \\
\hline \multicolumn{7}{|l|}{ Beer } \\
\hline Estonian & 53.1 & & & 16.7 & & \\
\hline Latvian & & 32.1 & & & 4.4 & \\
\hline Lithuanian & & & 46.5 & & & 8.1 \\
\hline Russian & $38.9^{\star \star}$ & 33.0 & $58.5^{\star}$ & $7.6^{\star \star \star}$ & 4.2 & 11.9 \\
\hline Other & 38.7 & 37.7 & 54.6 & 7.4 & 3.2 & 6.2 \\
\hline \multicolumn{7}{|l|}{ Wine } \\
\hline Estonian & 11.2 & & & 10.0 & & \\
\hline Latvian & & 3.1 & & & 1.6 & \\
\hline Lithuanian & & & 8.6 & & & 4.9 \\
\hline Russian & $4.4^{\star \star}$ & 5.1 & $17.7^{\star \star}$ & $5.6^{\star}$ & $3.6^{\star}$ & $14.9^{\star \star \star}$ \\
\hline Other & 5.7 & 2.6 & 10.7 & 4.4 & 0.7 & 7.1 \\
\hline \multicolumn{7}{|l|}{ Spirits } \\
\hline Estonian & 29.0 & & & 9.3 & & \\
\hline Latvian & & 16.6 & & & 2.5 & \\
\hline Lithuanian & & & 19.4 & & & 2.1 \\
\hline Russian & 26.2 & 16.1 & $28.7^{\star}$ & 9.3 & 2.6 & $7.0^{\star \star}$ \\
\hline Other & 30.1 & 17.6 & 32.1 & 4.4 & 0.8 & 4.1 \\
\hline
\end{tabular}

${ }^{\star}$ Different from Estonian ethnicity (for Estonia), Latvian ethnicity (for Latvia) or Lithuanian ethnicity (for Lithuania), $\mathrm{p}<0.05 ;{ }^{\star \star} \mathrm{p}<0.01 ;{ }^{\star \star \star} \mathrm{p}<0.001$.

Each of the countries is heterogeneous in terms of nationality, with large Russian minorities in Estonia and Latvia and, to a lesser extent in Lithuania. Lithuania also has significant
Polish, Ukrainian and Belarussian populations. Examination by nationality in each of the countries, after adjusting for age, produces a mixed picture (table 4). In Estonia, among both men and women, Estonians are more likely to drink weekly than are Russians, although the gap is wider for beer and wine than for spirits. In Latvia, there is very little difference between Latvians and Russians. In Lithuania, Russians are more likely to drink than are Lithuanians, with the other groups occupying an intermediate position. There are also considerable differences in the rates among Russians in each of the three countries and there is no consistent relation to the overall rates of consumption in each country.

Associations with age, nationality, area of residence, education and income were explored in a model in which odds ratios within categories of each variable were fully adjusted for all of the variables (table 5). In each country, for both sexes, increasing age was strongly associated with a lower likelihood of consuming alcohol weekly ( $\mathrm{p}$ value for trend $<0.001$ ). Differences associated with nationality in Estonia and in Lithuanian men remained significant, showing that they could not be accounted for factors such as income or education. Among men, analysis by education showed a mixed picture, with no difference in Estonia, a

Table 5 Odds ratios (OR) for the likelihood of consuming alcoholic beverages at least once a week, by country and gender

\begin{tabular}{|c|c|c|c|c|c|c|c|c|c|c|c|c|}
\hline & \multicolumn{4}{|c|}{ Estonia } & \multicolumn{4}{|c|}{ Latvia } & \multicolumn{4}{|c|}{ Lithuania } \\
\hline & \multicolumn{2}{|c|}{ Adjusted for age } & \multicolumn{2}{|c|}{ Adjusted for all variables } & \multicolumn{2}{|c|}{ Adjusted for age } & \multicolumn{2}{|c|}{ Adjusted for all variables } & \multicolumn{2}{|c|}{ Adjusted for age } & \multicolumn{2}{|c|}{ Adjusted for all variables } \\
\hline & OR & $95 \% C I$ & $O R$ & $95 \% C I$ & $O R$ & $95 \% C I$ & $O R$ & $95 \% C I$ & $O R$ & $95 \% C I$ & $O R$ & $95 \% C I$ \\
\hline \multicolumn{13}{|l|}{ Men } \\
\hline \multicolumn{13}{|l|}{ Age (y) } \\
\hline $19-34$ & 1.00 & & 1.00 & & 1.00 & & 1.00 & & 1.00 & & 1.00 & \\
\hline $35-49$ & 0.89 & $0.66 ; 1.22$ & 0.91 & $0.66 ; 1.25$ & 1.04 & $0.77 ; 1.42$ & 1.09 & $0.80 ; 1.50$ & 0.70 & $0.51 ; 0.97$ & 0.69 & $0.50 ; 0.95$ \\
\hline $50-64$ & 0.40 & $0.28 ; 0.57$ & 0.37 & $0.25 ; 0.54$ & 0.53 & $0.38 ; 0.73$ & 0.52 & $0.36 ; 0.73$ & 0.37 & $0.26 ; 0.52$ & 0.41 & $0.28 ; 0.59$ \\
\hline \multicolumn{13}{|l|}{ Nationality } \\
\hline Native ${ }^{\star}$ & 1.00 & & 1.00 & & 1.00 & & 1.00 & & 1.00 & & 1.00 & \\
\hline Russian & 0.53 & $0.38 ; 0.74$ & 0.51 & $0.36 ; 0.71$ & 0.93 & $0.70 ; 1.23$ & 0.87 & $0.64 ; 1.18$ & 1.51 & $0.93 ; 2.46$ & 1.54 & $0.94 ; 2.51$ \\
\hline Other & 0.45 & $0.25 ; 0.79$ & 0.43 & $0.24 ; 0.77$ & 1.09 & $0.72 ; 1.67$ & 0.95 & $0.61 ; 1.47$ & 1.72 & $1.01 ; 2.93$ & 1.77 & $1.03 ; 3.05$ \\
\hline \multicolumn{13}{|l|}{ Area } \\
\hline Urban & 1.00 & & 1.00 & & 1.00 & & 1.00 & & 1.00 & & 1.00 & \\
\hline Rural & 1.10 & $0.83 ; 1.45$ & 1.07 & $0.80 ; 1.42$ & 0.76 & $0.58 ; 1.00$ & 0.80 & $0.59 ; 1.09$ & 0.84 & $0.63 ; 1.11$ & 0.95 & $0.70 ; 1.29$ \\
\hline \multicolumn{13}{|c|}{ Education level } \\
\hline Low & 1.00 & & 1.00 & & 1.00 & & 1.00 & & 1.00 & & 1.00 & \\
\hline Medium & 1.04 & $0.69 ; 1.57$ & 0.96 & $0.62 ; 1.47$ & 0.64 & $0.44 ; 0.93$ & 0.59 & $0.40 ; 0.87$ & 1.40 & $0.93 ; 2.12$ & 1.35 & $0.88 ; 2.05$ \\
\hline High & 1.08 & $0.71 ; 1.64$ & 0.97 & $0.62 ; 1.52$ & 0.90 & $0.64 ; 1.28$ & 0.77 & $0.53 ; 1.11$ & 1.61 & $1.12 ; 2.31$ & 1.48 & $1.01 ; 2.17$ \\
\hline \multicolumn{13}{|c|}{ Income level } \\
\hline Very low & 1.00 & & 1.00 & & 1.00 & & 1.00 & & 1.00 & & 1.00 & \\
\hline Low & 0.85 & $0.59 ; 1.22$ & 0.75 & $0.51 ; 1.10$ & 1.10 & $0.82 ; 1.49$ & 1.09 & $0.80 ; 1.49$ & 0.83 & $0.60 ; 1.16$ & 0.79 & $0.56 ; 1.11$ \\
\hline Medium & 0.72 & $0.49 ; 1.05$ & 0.67 & $0.45 ; 1.00$ & 1.95 & $1.28 ; 2.96$ & 1.88 & $1.20 ; 2.95$ & 0.95 & $0.61 ; 1.50$ & 0.82 & $0.51 ; 1.31$ \\
\hline High & 0.98 & $0.61 ; 1.57$ & 0.85 & $0.52 ; 1.41$ & 1.55 & $0.94 ; 2.53$ & 1.48 & $0.88 ; 2.49$ & 1.70 & $1.18 ; 2.46$ & 1.52 & $1.02 ; 2.27$ \\
\hline \multicolumn{13}{|l|}{ Women } \\
\hline \multicolumn{13}{|l|}{ Age (y) } \\
\hline $19-34$ & 1.00 & & 1.00 & & 1.00 & & 1.00 & & 1.00 & & 1.00 & \\
\hline $35-49$ & 0.66 & $0.49 ; 0.90$ & 0.67 & $0.49 ; 0.91$ & 0.66 & $0.41 ; 1.07$ & 0.67 & $0.41 ; 1.12$ & 0.67 & $0.46 ; 0.99$ & 0.62 & $0.41 ; 0.93$ \\
\hline $50-64$ & 0.15 & $0.09 ; 0.25$ & 0.18 & $0.11 ; 0.29$ & 0.23 & $0.13 ; 0.43$ & 0.25 & $0.13 ; 0.47$ & 0.30 & $0.19 ; 0.49$ & 0.32 & $0.19 ; 0.55$ \\
\hline \multicolumn{13}{|l|}{ Nationality } \\
\hline Native ${ }^{\star}$ & 1.00 & & 1.00 & & 1.00 & & 1.00 & & 1.00 & & 1.00 & \\
\hline Russian & 0.55 & $0.39 ; 0.78$ & 0.57 & $0.39 ; 0.81$ & 1.07 & $0.68 ; 1.71$ & 1.00 & $0.61 ; 1.65$ & 2.38 & $1.38 ; 4.09$ & 2.34 & $1.32 ; 4.14$ \\
\hline Other & 0.40 & $0.19 ; 0.84$ & 0.40 & $0.19 ; 0.85$ & 0.67 & $0.28 ; 1.60$ & 0.59 & $0.24 ; 1.45$ & 0.93 & $0.43 ; 2.01$ & 0.95 & $0.43 ; 2.09$ \\
\hline \multicolumn{13}{|l|}{ Area } \\
\hline Urban & 1.00 & & 1.00 & & 1.00 & & 1.00 & & 1.00 & & 1.00 & \\
\hline Rural & 1.05 & $0.77 ; 1.44$ & 1.04 & $0.76 ; 1.44$ & 0.73 & $0.45 ; 1.18$ & 0.98 & $0.57 ; 1.69$ & 0.52 & $0.34 ; 0.79$ & 0.70 & $0.44 ; 1.10$ \\
\hline \multicolumn{13}{|c|}{ Education level } \\
\hline Low & 1.00 & & 1.00 & & 1.00 & & 1.00 & & 1.00 & & 1.00 & \\
\hline Medium & 1.48 & $0.76 ; 2.89$ & 1.10 & $0.55 ; 2.19$ & 1.13 & $0.49 ; 2.61$ & 1.04 & $0.44 ; 2.44$ & 0.78 & $0.38 ; 1.62$ & 0.62 & $0.30 ; 1.30$ \\
\hline High & 1.95 & $1.00 ; 3.78$ & 1.31 & $0.65 ; 2.64$ & 2.00 & $0.92 ; 4.35$ & 1.58 & $0.71 ; 3.52$ & 1.58 & $0.83 ; 2.98$ & 1.07 & $0.55 ; 2.08$ \\
\hline Income leve & & & & & & & & & & & & \\
\hline Very low & 1.00 & & 1.00 & & 1.00 & & 1.00 & & 1.00 & & 1.00 & \\
\hline Low & 0.99 & $0.69 ; 1.41$ & 0.90 & $0.63 ; 1.30$ & 1.31 & $0.77 ; 2.24$ & 1.20 & $0.68 ; 2.11$ & 1.14 & $0.69 ; 1.88$ & 1.03 & $0.62 ; 1.72$ \\
\hline Medium & 1.45 & $0.99 ; 2.14$ & 1.31 & $0.87 ; 1.96$ & 2.42 & $1.20 ; 4.88$ & 2.15 & $1.03 ; 4.47$ & 1.90 & $1.05 ; 3.45$ & 1.54 & $0.83 ; 2.85$ \\
\hline High & 2.48 & $1.41 ; 4.34$ & 2.33 & $1.31 ; 4.15$ & 6.12 & $2.94 ; 12.72$ & 5.33 & $2.44 ; 11.61$ & 3.65 & $2.32 ; 5.74$ & 3.07 & $1.90 ; 4.96$ \\
\hline
\end{tabular}

${ }^{\star}$ Native designates Estonians in Estonia, Latvians in Latvia and Lithuanians in Lithuania respectively. 
Table 6 Mean daily alcohol intake (grams of alcohol) during the previous week and proportion of heavy drinkers (>80 g/d) by country, gender and age

\begin{tabular}{|c|c|c|c|c|c|c|c|c|c|c|c|c|}
\hline & \multicolumn{4}{|c|}{ Estonia } & \multicolumn{4}{|c|}{ Latvia } & \multicolumn{4}{|c|}{ Lithuania } \\
\hline & $n$ & $\begin{array}{l}\text { Mean (SD) } \\
g / d\end{array}$ & $\begin{array}{l}\text { Geometric } \\
\text { mean }\end{array}$ & $>80 \mathrm{~g} / \mathrm{d} \%$ & $n$ & $\begin{array}{l}\text { Mean (SD) } \\
g / d\end{array}$ & $\begin{array}{l}\text { Geometric } \\
\text { mean }\end{array}$ & $>80 \mathrm{~g} / \mathrm{d} \%$ & $n$ & $\begin{array}{l}\text { Mean (SD) } \\
g / d\end{array}$ & $\begin{array}{l}\text { Geometric } \\
\text { mean }\end{array}$ & $>80 \mathrm{~g} / \mathrm{d} \%$ \\
\hline \multicolumn{13}{|c|}{ All respondents } \\
\hline \multicolumn{13}{|c|}{ Men } \\
\hline All & 901 & $29(42)$ & 2.1 & 9.3 & 1055 & $15(23)$ & $0.5^{\mathrm{a}}$ & 2.7 & 978 & $18(24)$ & $1.2^{\mathrm{b}, \mathrm{c}}$ & $2.5^{\mathrm{d}}$ \\
\hline $19-34$ & 397 & $29(43)$ & 2.7 & 8.8 & 335 & $16(25)$ & $1.0^{\mathrm{a}}$ & 3.6 & 350 & $20(22)$ & $2.4^{\mathrm{c}}$ & $2.6^{\mathrm{d}}$ \\
\hline $35-49$ & 320 & $33(46)$ & 3.8 & 11.9 & 371 & $16(22)$ & $0.8^{\mathrm{a}}$ & 2.4 & 357 & $20(28)$ & $1.7^{\mathrm{b}}$ & $2.8^{\mathrm{d}}$ \\
\hline $50-64$ & 184 & $20(31)$ & 0.5 & 6.0 & 349 & $13(22)$ & 0.3 & 2.0 & 271 & $14(20)$ & 0.3 & $1.9^{\mathrm{e}}$ \\
\hline \multicolumn{13}{|l|}{ Women } \\
\hline All & 1109 & $6(12)$ & 0.1 & 0.5 & 1203 & $3(7)$ & $0.02^{\mathrm{a}}$ & 0.2 & 1159 & $3(7)$ & $0.04^{\mathrm{a}, \mathrm{f}}$ & 0.2 \\
\hline $19-34$ & 459 & $7(14)$ & 0.1 & 0.9 & 340 & $4(8)$ & $0.1^{\mathrm{b}}$ & 0.0 & 359 & $4(6)$ & 0.1 & $0.0^{\mathrm{e}}$ \\
\hline $35-49$ & 376 & $6(12)$ & 0.1 & 0.5 & 394 & $4(9)$ & $0.0^{\mathrm{b}}$ & 0.5 & 407 & $3(6)$ & 0.0 & 0.0 \\
\hline $50-64$ & 274 & $3(8)$ & 0.0 & 0.0 & 469 & $2(4)$ & $0.01^{\mathrm{b}}$ & 0.0 & 393 & $3(8)$ & 0.0 & 0.5 \\
\hline \multirow{2}{*}{\multicolumn{13}{|c|}{$\begin{array}{l}\text { Respondents who consumed alcohol during the previous week } \\
\text { Men }\end{array}$}} \\
\hline & & & & & & & & & & & & \\
\hline All & 694 & $37(45)$ & 21.1 & 12.1 & 693 & $22(25)$ & $14.6^{\mathrm{a}}$ & 4.0 & 711 & $25(25)$ & $17.0^{\mathrm{a}, \mathrm{f}}$ & $3.4^{\mathrm{d}}$ \\
\hline $19-34$ & 315 & $37(46)$ & 21.6 & 11.1 & 224 & $23(27)$ & $14.8^{\mathrm{a}}$ & 5.4 & 279 & $25(22)$ & $17.1^{\mathrm{b}}$ & $3.2^{\mathrm{d}}$ \\
\hline $35-49$ & 263 & $40(48)$ & 22.4 & 14.4 & 258 & $23(24)$ & $15.9^{\mathrm{a}}$ & 3.5 & 271 & $27(29)$ & $17.4^{\mathrm{b}}$ & $3.7^{\mathrm{d}}$ \\
\hline $50-64$ & 116 & $31(35)$ & 17.4 & 9.5 & 211 & $21(25)$ & $13.1^{\mathrm{b}}$ & 3.3 & 161 & $23(21)$ & 16.1 & $3.1^{\mathrm{e}}$ \\
\hline \multicolumn{13}{|l|}{ Women } \\
\hline All & 523 & $13(15)$ & 8.0 & 1.1 & 426 & $8(10)$ & $5.6^{\mathrm{a}}$ & 5.6 & 483 & $8(9)$ & $5.6^{\mathrm{a}}$ & 0.4 \\
\hline $19-34$ & 246 & $13(16)$ & 8.4 & 1.6 & 159 & $9(10)$ & $5.7^{\mathrm{a}}$ & 0.0 & 186 & $7(6)$ & $5.5^{\mathrm{a}}$ & 0.0 \\
\hline $35-49$ & 189 & $13(14)$ & 8.2 & 1.1 & 159 & $9(13)$ & $6.0^{\mathrm{b}}$ & 1.3 & 181 & $7(7)$ & $2.0^{\mathrm{a}}$ & 0.0 \\
\hline $50-64$ & 88 & $10(12)$ & 6.3 & 0.0 & 108 & $7(7)$ & 5.0 & 0.0 & 116 & $9(13)$ & 6.1 & 1.7 \\
\hline
\end{tabular}

${ }^{\mathrm{a}}$ Different from Estonia, $\mathrm{p}<0.001$; ${ }^{\mathrm{b}}$ Different from Estonia, $\mathrm{p}<0.05$; ${ }^{\mathrm{c}}$ Different from Latvia, $\mathrm{p}<0.001$; ${ }^{\mathrm{d}}$ Variations among countries for the proportion of heavy drinkers, $\mathrm{p}<0.001$; ${ }^{\circ}$ Variations among countries for the proportion of heavy drinkers, $\mathrm{p}<005$; ${ }^{\mathrm{f}}$ Different from Latvia, $\mathrm{p}<0.05$.

higher frequency of drinking among those with the highest level of education compared with the lowest in Lithuania, and a lower rate among those with middle level education than those with the lowest category in Latvia. Among women, a higher consumption rate among women with higher education in Estonia failed to reach significance in the fully adjusted model.

In Latvia and Lithuania, the odds of consuming alcohol at least once a week tended to be higher among men in higher income categories; however, the gradient was much more marked among women from each country ( $p$ value for trend $<0.005$ ), with those in the highest income categories between twice and five times as likely to drink as those in the lowest category. The gradient was especially marked in Latvia.

Turning to the amount drunk, the mean daily consumption, in grams, is shown in table 6 , as is the percentage of heavy drinkers (respondents drinking greater than $80 \mathrm{~g} /$ day). Mean daily consumption was lower in Latvia than in the other countries, with Lithuania being in an intermediate position below Estonia. The percentage of heavy drinkers is much higher in Estonia than in the other countries, at almost one in 10 men. Heavy drinking is rare among women in all countries. Considering only those who reported drinking in the previous week, amounts drunk, as well as the percentage who drink heavily, are very much lower among women than men in all of the countries.

\section{Discussion}

Before discussing the results, the limitations of the survey must be considered. Although the overall sample was relatively large, the small size of certain groups reduced the power to detect significant differences. However, the major weakness was that, because the survey was primarily designed to obtain data on nutrition rather than on alcohol consumption, the questions on drinking were rather basic and did not include any of the standard instruments to detect problem drinking or to generate a quantity/frequency matrix. Consequently, these surveys do not provide information on pattern of drinking and, in particular, binge drinking, a phenomenon that is increasingly being recognised as important in this region. ${ }^{7}$ None the less, the surveys do provide information against which future trends can be measured.

All surveys of alcohol consumption are notoriously problematic. ${ }^{8}$ Difficulties include inaccurate categorisation of alcohol intake as people underestimate or distort their consumption. ${ }^{9}$ However, in countries such as these, where heavy drinking is common it may be that there is less social stigma about admitting to it. Importantly, where it is possible to make direct comparisons, these data are very similar to those from the FinnBalt surveys on health behaviour, ${ }^{1011}$ undertaken at intervals since 1990 in all three countries. The only differences are a slightly higher frequency of beer drinking among Estonian men and a lower frequency of spirit drinking among Lithuanian women in this survey.

With these caveats, several observations can be made. In each country, most men drink regularly. Among women, drinking is less common in each country but there is also a marked decline with age, so that less than one in 12 women aged over 50 drinks regularly. In general, higher education and income are associated with a greater probability of drinking.

Although the three countries are frequently considered together, in view of their shared recent history, there are marked differences between them. Perhaps the most surprising finding is that the relations between rates in the majority population and the Russian minorities are so variable, and that the rates in the Russian populations in each country vary so much. The finding that urban-rural and educational and income differences are much 
greater in Lithuania than in Estonia is consistent with data on patterns of smoking. ${ }^{12}$ Lithuania still has a very large, and quite traditional, rural agricultural sector whereas many Estonians living in rural areas work in towns and cities.

These data indicate that alcohol should be a concern for public health in this region, with almost one in 10 Estonian men drinking at a level that equates to $80 \mathrm{~g}$ per day. This level is associated with a greatly increased risk of many of the manifestations of physical harm attributable to drinking. ${ }^{13}$ This is very much higher than in the other two countries, although even there the rates among younger men are approximately one in 30 . However, the absence of data on pattern of drinking means that this may underestimate the harmful effects and, on the basis of data from a comparable, but more detailed survey from Russia, there may be many more people who, while recording only moderate weekly consumption, may be drinking huge quantities during a single episode. ${ }^{14}$

Although, at an aggregate level, it is impossible to assess the impact of particular factors to the patterns recorded, it may be helpful, when interpreting these data, to take account of changes in policies related to alcohol. In the period 1989 to 1994 , it is reported that prices of beer and wine increased in real terms in Estonia, with the price of spirits remaining stable. In Lithuania, prices of all types of alcohol increased, whereas in Latvia they all decreased.

These findings must, however, be interpreted in the light of the earlier comments on the scale of smuggling and illicit production. Estonia bans advertising of alcohol on television and radio but a ban on advertising in print media and on billboards only covers wine. Lithuania has a general ban on advertising of spirits and wine but no restriction on beer. The legal restrictions in Latvia are confined to the capital, Riga. In each country, however, enforcement varies. In Latvia, there have been discussions on hypothecation of taxes on alcohol for prevention and treatment of alcoholism.

Evidence of the adverse health effects of high levels of alcohol consumption in the three Baltic Republics has been apparent for some time.
These surveys now provide some information that will help create integrated, intersectoral policies to tackle them, although clearly much more detailed research is needed to understand the reasons why people drink heavily and the context in which they do so.

We are grateful to the following who assisted with organisation of the surveys: Roma Bartkeviciute, $\mathrm{MD}, \mathrm{PhD}$, Head of Department of National Nutrition Centre, Kalvariju str 153, 2042, Vilnius, Lithuania; Dr Mary Serdula, Department of Nutrition, CDC, Atlanta, USA; Dr Ritva Prõttala, Institute of Public Health, Helsinki, Finland; Mr Eric Poortvliet, Unit for Preventive Nutrition, Novum, 14151 Huddinge, Sweden.

Funding: the surveys were funded by the Ministry of Foreign Affairs, Luxembourg and WHO and the work of ECOHOST is supported by the UK Department for International Development. However neither DfID, the Government of Luxembourg mont. However neither DfID, the Government of Luxembourg nor WHO can accept any resp
provided or views expressed.

Conflicts of interest: none.

1 McKee M, Chenet L. Alcoholism and rising mortality in the Russian Federation. BMF 1995;310:1668-9.

2 Leon D, Chenet L, Shkolnikov VM, et al. Huge variation in Russian mortality rates 1984-1994: artefact, alcohol, or what? Lancet 1997;350:383-8.

3 Britton A, McKee $M$. The relation between alcohol and cardiovascular disease in Eastern Europe: explaining the paradox. F Epidemiol Community Health 2000;54:328-32.

paradox. F Epidemiol Community Health 2000;54:328-32.
4 Walberg P, McKee M, Shkolnikov V, et al. Economic Walberg $\mathrm{P}$, McKee $\mathrm{M}$, Shkolnikov V, et al. Economic
change, crime, and mortality crisis in Russia: a regional analysis. $B M F$ 1998;317:312-18.

5 WHO. Health for all database. Copenhagen: WHO, 1998

6 Harkin AM, Anderson P, Goos C. Smoking, drinking and drug taking in the European Region. Copenhagen: WHO, 1997.

7 McKee M, Britton A. The positive relationship between alcohol and heart disease in eastern Europe: potential physiological mechanisms. fR Soc Med 1998;91:402-7.

8 Klatsky AL.Epidemiology of coronary heart diseaseKlatsky AL. Epidemiology of coronary heart disease-
Influence of alcohol. Alcohol Clin Exp Res 1994;18:88-96.

9 Embree BG, Whitehead PC. Validity and reliability of self-reported drinking behaviour: dealing with the problem of reporting bias. F Stud Alcohol 1998;54:334-44.

10 Grabauskas V, Klumbiene J, Petkeviciene J, et al. Suaugusiu Lietuvos zmoniu gyvensenos tyrimas, 1996. [Health behaviour survey among Lithuanian adult population, Spring 1996. Helsinki: KTL, 1998.

11 Kasmel A, Lipand A, Kasmel K, et al. Eesti taikasvanud elanikkonna tervisekäitumise uuring, kevad 1996. [Health behavnikkonna tervisekäitumise uuring, kevad 1996. [Health behav-
iour among Estonian adult population.] Helsinki: KTL, 1997.

12 Pudule I, Grinberga D, Kadziauskiene K, et al. Patterns of smoking in the Baltic Republics. I Epidemiol Community Health 1999;53:277-83.

13 Anderson P. Alcohol and the risk of physical harm. In: Holder HD, Edwards G, eds. Alcohol policy and public policy: evidence and issues. Oxford: Oxford Medical Publications, 1995:38-61.

14 Bobak M, McKee M, Rose R, et al. Alcohol consumption in a national sample of the Russian population. Addiction 1999;94:857-66. 